\title{
Deformation and power characteristics monolithic reinforced concrete bearing systems in the mode of progressive collapse
}

\author{
Oleg Kabantsev* and Bozidar Mitrovic \\ Moscow State University of Civil Engineering, Yaroslavskoe shosse, 26, Moscow, 129337, Russia
}

\begin{abstract}
The paper considers the question of substantiating the choice of criteria for limiting states of monolithic reinforced concrete bearing systems for the regime of progressive collapse. Based on the results of computational and theoretical studies, structural elements and structural units of monolithic reinforced concrete buildings are determined, the destruction of which occurs first of all in the event of a failure of the vertical bearing structure. It is established that the destruction of such structural units and structural elements leads to the initialization of the process of progressive collapse. A computational and theoretical analysis has been performed to determine the ultimate deformation effects or load values according to the criteria for the bearing capacity of crutial units of monolithic reinforced concrete systems with different span sizes. It is established that as a basic criterion for estimating the stress-and-strain state of monolithic reinforced concrete structures for the mode of failure of a vertical bearing structure, the relative deformation amount corresponding to the formation of the "fracture" zone of the retaining section of the overlap under the action of transverse forces can be adopted.
\end{abstract}

\section{Introduction and task statement}

Stability evaluation of the load-bearing system in the event of individual load-bearing structure failure or when a local defect is created in the structural system is one of the most important tasks when assessing the safety level of the building bearing system in its entirety. In some cases, this task is stated as an estimate of the structure survivability [1, 2, 3] which seems to be a justified approach. The legislative document in force [4] outlines requirements to ensure mechanical safety of buildings and structures in the event of an emergency design situation: 'when designing a facility of an increased criticality rating, an emergency design situation must also be taken into account ... which is important from the point of view of the consequences of reaching the limit states that can be generated in this situation (including the limit states arising in connection with explosion, collision, emergency situation, fire, and also right after the failure of one of the supporting structures)'. Following further description of the requirements [4], the state standard [5] introduces a new kind of limit state: 'special limit states, namely the states arising from

* Corresponding author: ovk531@gmail.com 
particular impacts and situations exceeding of which leads to the failure of structures with disastrous consequences'.

The definition of special effects is studied in detail by Code of Regulations [6] which defines that 'the impact caused by particular emergency effects needs to be taken into account in the calculation to determine the structures progressive collapse. ... Calculation for the structures progressive collapse may be considered not compulsory if special measures are ensured which exclude progressive collapse of a structure or part thereof'. At that, the wording of the standard [5] contains certain criteria only for previously known and used in practice limit states of the first and second groups. The new term 'special limit state' is not given any regulatory definitions or characteristics.

Consequently, the compliance with the requirements of the Russian Federation legislation in force and regulatory documents covering the analysis of the stability of the load-bearing system in the event of individual load-bearing structure failure (i.e. in response to a special limit state) is not fully grounded by the regulatory criteria; and this leads to ambiguity in approaches to assess the stability of load-bearing systems with progressive collapse and to evaluate the efficiency of 'special measures which exclude the progressive collapse of a structure or part thereof'.

In order to justify the approaches to the special limit states criteria evaluation, it is required to determine the operational aspects of the supporting system of the building structure when one of the supporting elements fails. One of the initial guidelines and regulations dealing with the problems of progressive collapse [7] outlines that 'stability of a building against progressive collapse will be ensured if the following condition is met for any element:

$$
F \leq S
$$

where $F$ and $S$ are force in the element taken from the elastic analysis and its design load-bearing capacity respectively calculated taken into account the guidance of Item 3 [7]'. Pursuant to [7], it can be admitted that the structures are operated under the conditions of plastic deformations development; still the degree of plastic deformations is determined implicitly, namely through the coefficients of reliability to the strength characteristics of the materials.

The operational principle of the structure in the mode of inelastic (plastic) deformation under special conditions of the operational period is widely used: in the context of seismic and explosive effects, in the conditions of the work sites. Thus, in [8] there is a method proposed to take into account the inelastic deformation of the building structures under seismic effect based on the parameter 'building state in the aftermath of an earthquake which is defined as the maximum tolerated value of 'residual deformations'. The author of [8] shows that 'residual deformations' are the result of the structures operational condition outside the elastic phase.

Theoretical studies to determine 'permissible damage-behavior ratio' are normally based on plasticity characteristics of the structure (plasticity coefficient $\mu$ ), or on the structural damage parameter ('damage index of the structure' $D$ ); for details see further [9, $10,11,12,13,14]$ in which various approaches to determine these parameters are proposed: a) by curvature (for reinforced concrete elements); b) by plastic range of turning angle (for reinforced concrete elements); c) by limit state of deflection; d) by accumulation of damage (for reinforced concrete elements); e) by stiffness reduction when loading reinforced concrete elements (criteria parameter is the section curvature); f) based on fatigue assessment; g) based on absorption of energy by the structure, and by a number of other ones.

In [15] the method of estimating the permissible level of damage is described based on the plasticity coefficient $\mu$ determined by deformation characteristics; therein the method is 
further justified for the most frequently implemented reinforced concrete bearing structures of various types

$$
\mu=\varepsilon_{t o t} / \varepsilon_{e l}
$$

where $\varepsilon_{t o t}$ and $\varepsilon_{e l}$ are total and elastic relative strains of the structure respectively.

In this regard, for the value of total relative strain there should be set reasonable restrictions. For instance, for the basic structural anisotropic materials the following value is deemed reasonable:

$$
\varepsilon_{\max }=0.85 \varepsilon_{\text {tot }}
$$

It should be noted that, according to the described above method, the plasticity coefficient $\mu$ is determined on the basis of deformation parameters subject to thorough control and that provides for an acceptable accuracy level.

In order to protect the load-bearing systems against progressive collapse, various approaches are proposed, i.e. the method of the load-bearing capacity increase for the structural elements beyond the required results generated by elastic calculation. For the most common types of load-bearing systems, namely multi-storey and high-rise buildings with the load-bearing structures of monolithic reinforced concrete, the method of protection against progressive collapse based on the arrangement of floors of the increased stiffness (outrigger floors) is proposed and justified (ref. [16]); the method ensures a change in operational pattern of the vertical support structure in the event of failure of the underlying element; such a structure gets 'suspended' to the outrigger floor. The operating principle of the outrigger floor as a structural unit ensuring 'suspension' of vertical bearing structures is fully consistent with the definition of a 'special measure excluding progressive collapse of the structure or part thereof, which contributes to its wide implementation in high-rise reinforced concrete construction projects.

Nonetheless, the absence of sufficient characteristics of the limit states of the loadbearing structures for a special limit state in the event of failure of a bearing element with allowance for the tolerated level of plastic deformation of the structures does not permit to fully and reasonably take into account the plastic phase of the operation of the outrigger floors structures which seems completely admissible.

Apparently, the value of the plastic phase degree for the structure operation should have reasonable limitations. Such limitations are determined not only by the layout of the outrigger floors, but also by the condition of all other elements of monolithic reinforced concrete bearing system. Thus, as stated in [17], the most sensitive elements of the main load-bearing system of a reinforced concrete building are monolithic reinforced concrete floors. In light of the analysis outcome, it is proved in [17] that localized fractures are formed primarily in the near-supporting zones. The extent of such localized fracture zones and their characteristics are mainly determined by the structural rigidity of the outrigger floor. It is evident that it is feasible to build an outrigger floor of massive structures of high rigidity that will solely operate in the elastic stage and which will ensure minimal deformation values of the suspended ceiling. Nevertheless, such methods to ensure protection against progressive collapse conflict with the reasoning of economic feasibility. 


\section{Models of monolithic reinforced concrete structures to proceed with the analysis of the fractures formation under the conditions of failure of an element of the carrier system}

In order to determine the utmost tolerated deformations in the structures of outrigger floors, it is compulsory to analyze the processes of the fractures formation in the core elements of the bearing system (monolithic reinforced concrete slabs), as well as the mechanisms leading to the formation of such fractures. Within the scope of this study, such analysis is performed by numerical methods based on finite element models of typical floors of different dimensions of spans and structures stepping: from 3.0 to $7.2 \mathrm{~m}$ (the general view of the model is shown in Fig. 1).

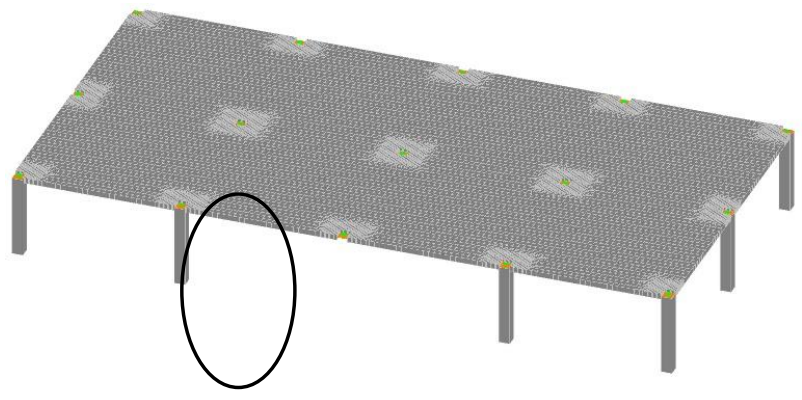

Fig. 1. General view of the typical floor model with spans of $6,0 \mathrm{~m}$. Circled in the centre is the zone where a column in the last row is missing ('failure' of the structure).

The design model corresponds to a typical floor slab with a set of supporting vertical structures, namely columns. The design analysis is performed in the mode of examination of the bearing capacity of the reinforced concrete section using the SCAD computing complex [18]. The analysis of the load-bearing capacity of the elements of the slab model is carried out in accordance with the provisions of the current norms [19]. The monolithic reinforced concrete slab is approximated by finite shell-type elements as per the MindlinReissner plate theory with the finite elements dimensions of $200 \times 200 \mathrm{~mm}$ (main slab surface) and 50x50 mm (in the near-support zone). The contact zone between the column and slab is modeled using an all-solid body.

In view of the impact, the movement of the support zones of the slab above the 'failed' column was considered. The displacement varied from zero to the 'tolerated' value (spaced at $0.5 \mathrm{~mm}$ ) corresponding to the moment of formation of the fracture zone (Fig. 2).

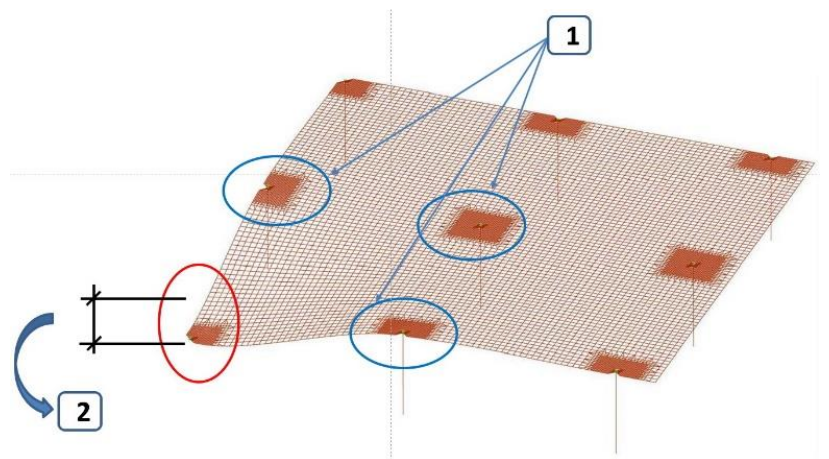

Fig. 2. Layout of the design model and deformation load effect created in order to analyze the fracture process of the near-support zones of the slabs. 1 - zones under analysis to determine load-bearing capacity; 2 - deformation effect. 


\section{Numerical studies outcome for the elements limit states in the monolithic reinforced concrete bearing systems in the event of failure of the support structures}

The following is proved to be the result of the numerical experiment:

The process of the fracture formation in the slabs in the near-support zone has a dominant consistent character: the exhaustion of the bearing capacity begins with single finite elements and when the load factor (displacement value) increases; the number of 'destroyed' finite elements increases with the formation of the 'destroyed' finite elements within one surface of the column support loop, and which corresponds to 'destruction' of the near-support zone (Fig. 3).
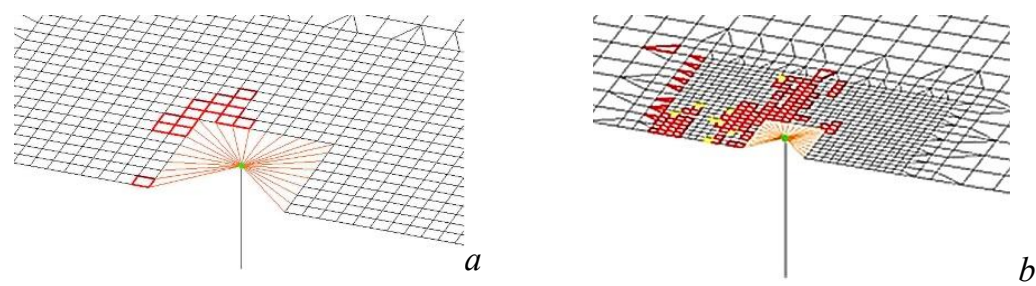

Fig. 3. Various phases of fracture formation of the near-support slab zone. $a$ - 'destruction' of single finite elements, $b$ - formation of the area of 'destructed' finite elements within one surface of the column support loop.

Destruction of the near-support slab zone measured by different criteria (transverse force and bending moment) occurs at quite different displacement values of the section above the failed support element: formation of the destroyed near-support zone occurs at significantly lower transverse forces than if compared with the bending moment criterion (Fig. 4).

The values of 'marginal' displacements (in absolute values) correlate well with 'failures' of the same type of support structures (middle column, edge column, corner column) with increase in span of the slab (Fig. 5).

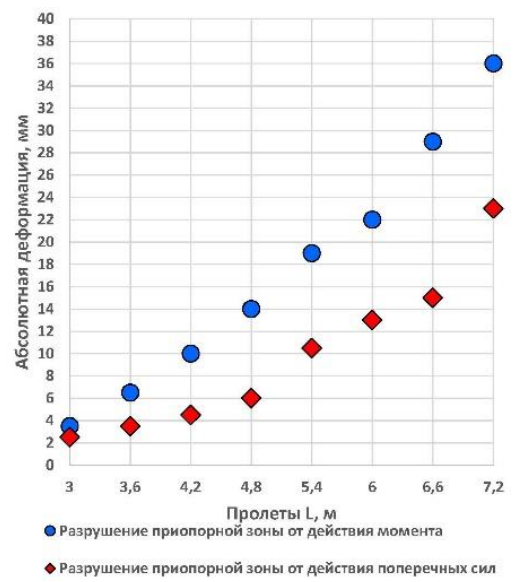

Fig. 4. Values of 'tolerated' displacements for various criteria of formation of the near-support slab zone (middle column). 


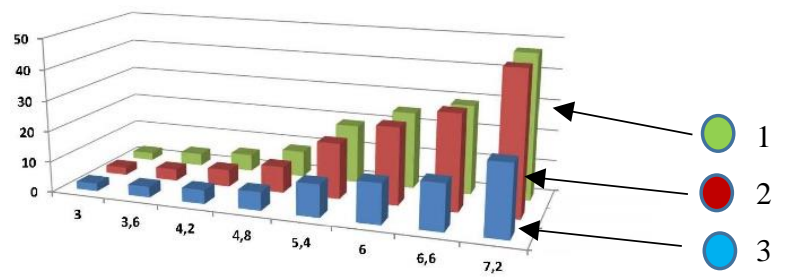

Fig. 5. Values of 'tolerated' displacements in relative values for various spans/steps of the support slab structures ( 1 - corner column; 2 - the column extremes of the series; 3 - middle column).

The outcome of the applied forces determination equivalent to the values of 'tolerated' displacement values in comparison with deformation effects prove that there is no correlation between force and deformation effects (Fig. 6). Consequently, the use of the force impact does not provide a correct estimate and cannot be considered as a criteria parameter.

The obtained values of the 'tolerated' displacements corresponding to the formation of the 'fracture' in the near-support zone under the conditions of failure of the support structure enable to proceed with the calculations of the utmost permissible values of the plasticity coefficients $\mu$ (in accordance with (2)) and shift to determining the values of the admissible damages (as per [21]).
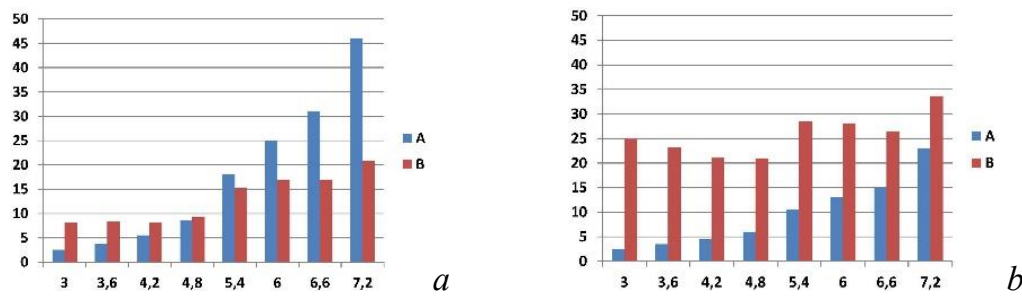

Fig. 6. Comparison of the applied load factors for the conditions of formation of 'destruction' of the near-support slab zone. $a$ - failure of the edge column, $b$ - failure of the middle column. On the vertical axis given are the absolute values of displacements $(\mathrm{mm})$ and the values of the tolerated force factor (tons); $\mathbf{A}$ - is the deformation and $\mathbf{B}$ - is the force factors.

Based on the results of the performed numerical studies, the plasticity coefficients corresponding to the maximum permissible deformations for different spans of the bearing system are obtained. For instance, the coefficients of plasticity in the event of 'failure' of the corner column are given in Fig. 7.

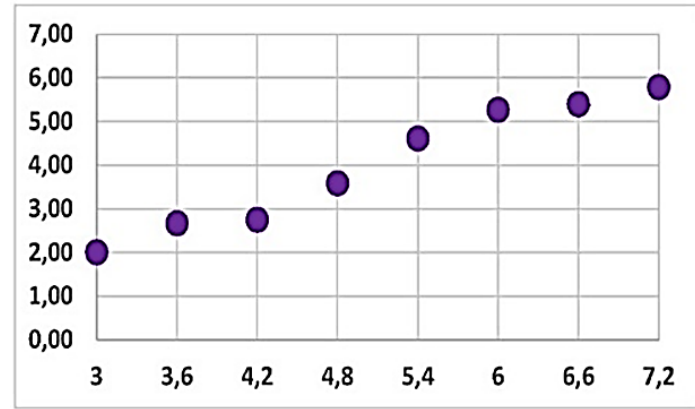

Fig. 7. Coefficients of plasticity $\mu$ in the event of 'failure' of the corner column. 
Availability of the reasonable values of tolerated plasticity of the core elements of monolithic reinforced concrete bearing systems is the basis for further determination of the values of the level of permissible damage which allows for correct assessment of the outrigger floors operation efficiency as '... a special measure that prevents against progressive collapse of the structure or part thereof'.

\section{Conclusion}

The undertaken studies justify the possibility to use deformation criteria to estimate the stress-strain state of the monolithic reinforced concrete structures under the conditions of failure of the vertical element of the bearing system. The studies prove that as the main criterion to assess the stress-strain state for the monolithic reinforced concrete structures there can be considered relative deformation corresponding to the formation of the 'fracture' area of the near-support slab zone under the impact of transverse forces.

The force factors modeling the impact in the failure mode of the bearing structure do not reveal acceptable correlation with the exhaustion of the bearing capacity of the nearsupport slab zone, which does not allow them to be taken into account while analyzing the processes taking place in the monolithic reinforced concrete bearing systems under the conditions of progressive collapse.

The determined characteristics of ultimate plasticity and corresponding characteristics of the level of permissible damage, in fact, prove to be the characteristics of the limit states of monolithic reinforced concrete structures for the progressive collapse mode.

\section{References}

1. Kolchunov V.I., Klyueva N.I., Androsova N.B., Buchtiyarova A.S. Survivability of buildings and structures under the impacts beyond the design. ASB, Moscow. (2014)

2. Klyueva N.I., Korenkov P.A. Nonresidential industrial and civil engineering. Experimental determination methods to define survivability criteria for reinforced concrete frame-rod structural systems. 2, 44-48 (2016)

3. Bondarenko B.M., Kolchunov V.I. Nonresidential industrial and civil engineering. Concepts and development trends in the structural safety theory for buildings and structures under the impact of stress and environmental effects. 2, 28-31 (2013)

4. Federal Law no.384 on Technical regulations on the safety of buildings and structures.

5. State standard GOST 27751-2014 on Reliability of building structures and foundations. Main provisions.

6. Code of Practice SP 296.1325800.2017. Buildings and Structures. Special effects. Ministry of construction of Russia. Moscow, 27 (2017)

7. Guidelines on residential buildings design // TsNIIEP of Residential Buildings under Goskomarchitectura. Rev. 3. Residential buildings design (an integral part of SNip 2.08.01-85). Moscow, 304 (1898)

8. Oizerman V.I. Modeling of structures to withstand seismic effects employing the method of limit states. Abstract TsINIS, Series XIV, rev. 9. 4-7 (1978)

9. Simport E. Engineering and construction journal. Reduction coefficient selection procedure under seismic loads K1 under the given range of plasticity coefficient $\mu .1$ 44-52 (2012)

10. Rutman Y.L. Bulletin of civil engineers. Reduction coefficient selection under seismic loads based on the plasticity analysis of the entire structure. 2, 78-81 (2011) 
11. Mkrtychev O.V. Problems of accounting for non-linearities in the theory of seismic stability (assumptions and deviations), MGSU, Moscow. 192 (2012)

12. Fajfar P. Soil Dynamic and Earthquake Engineering. A measure of earthquake motion capacity to damage medium-period structures. 9, 236-242 (1990)

13. Nadim F. Bulletin of Earthquake Engineering. The Bam Earthquake of 26 December 2003, Kluwer Academic Publishers, Printed in the Netherlands. 2, 119-153 (2004)

14. Rahai A. Concrete Structures, Evaluation of Behavior and Strengthening Method. 362 (2003)

15. Popov N.N. Rastorguyev B.S., Zabegayev A.V. Modeling of structures for dynamic and special loads., Vysshaya Shkola, Moscow. 319 (1992)

16. Kabantsev O.V. Some issues related to normalization of calculations of the reinforced concrete structures of high-rise buildings. Transregional public organization Assistance in development and application of spatial structures in construction. Proc. of the scientific session reports, Moscow. 36-39 (2009)

17. Domarova E.V. MGSU Bulletin. Evaluation of resistance to the progressive destruction of the monolithic reinforced concrete frame buildings with individual reinforced floors. 2, 22-29 (2014)

18. Karpilovsky V.S., Kriksunov E.Z., Malyarenko A.A., Mikitarenko M.A., Perelmuter A.V., Perelmuter M.A. SCAD Office. Version 21. Software complex SCAD++. Publishing house SKAD SOFT, Moscow. 808 (2015)

19. Code of Practice SP 63.13330.2012 Concrete and reinforced concrete structures. Main provisions. Revised edition of SNiP 52-01-2003. FAU FTsC, Moscow, 156 (2012)

20. Kabantsev O.V., Karlin A.V., Pesin K.O. International Journal for Computational Civil and Structural Engineering. Stress-strain state analysis of plate structures in the nearsupport zones. 13, 55-62 (2017)

21. Kabantsev O.V. Bulletin of Tomsk State Architecture and Construction University. Tomsk. On defining the value of tolerated damages Kl of the structures resistant to seismic effects. 2, 117-129 (2016) 